\title{
Assessing the influence of nutrition education among adolescent Girls (I3-16years)
}

\begin{abstract}
Good nutrition is a pillar of development and not only because food is the most basic human need. Moreover, to achieve optimal physical growth and development, adolescents require adequate nutrition as well as physical activity to support muscle development and bone health. Without proper nutrition, health is impossible. The main objective of the current study is to assess the influence of nutrition education regarding balanced diet and physical activity among adolescent girls of Govt. Islamia girls' high school. Through random sampling 30 students were taken from four section of each class from Govt. Islamia girls high school Lahore cant in order to take pre-test and post-test. Questionnaire has been utilized as a data collection tool to providing nutrition information. Lecture delivered by using pictorial presentations regarding balanced diet, physical activity, food pyramid, food guidelines, my plate, macro nutrient, micro nutrient and five food groups. The results showed remarkable change in the adolescent's nutritional knowledge regarding balanced diet and physical activity at $\alpha$ level of 0.005 . The study was concluded that multimedia presentations, $3 \mathrm{~d}$ movies were used for adolescents learning. The nutritional activities should be made to encourage adolescents for healthy diet and healthy lifestyles.
\end{abstract}

\author{
Volume 6 Issue 4 - 2017
}

\author{
Rashida Perveen,' Anam Raiz,' Usman Mir \\ $\mathrm{Khan}^{2}$ \\ 'Department of Home Economics (Food and Nutrition), Lahore \\ College for Women University, Pakistan \\ ${ }^{2}$ Department of Dairy Technology, University of Veterinary \& \\ Animal Sciences, Pakistan
}

Correspondence: Rashida Perveen, Department of Home Economics (Food and Nutrition), Lahore College for Women University, Lahore, Pakistan, Email rashidaparveenft@yahoo.com

Received: February 18, 2017| Published: April 17, 2017

\section{Introduction}

Food and eating are intimately connected with eating disorders and body image. The "intuitive eating", promote healthy eating attitudes without increasing an unhealthy focus on restrictive eating or promoting a poor body image. The health promoting schools use a whole-school approach to enhance the health and educational outcomes of adolescents through teaching and learning experiences initiated in the schools. The "Intuitive eating" approaches encourage individuals to focus on internal body signals as a guide for eating, and have been shown to have a positive impact on eating-related psychological outcomes in adults.

Adolescence is a period of rapid physical growth resulting from the simultaneous release of various growth, thyroid and sex hormones. At the most rapid period of growth following childhood, adolescents grow at a rate nearly identical to that of a toddler, during which time bones become harder, muscle development increases and heart and lungs increase in both size and capacity. Moreover to achieve optimal physical growth and development, adolescents require adequate nutrition as well as physical activity to support muscle development and bone health. The higher physical activity is associated with better health-related quality of life across the domains of physical social and cognitive functioning in adolescents. ${ }^{2}$

School-based nutrition education research studies were based primarily on a knowledge-attitude-behavior approach, while disease reduction/health enhancement studies were behaviorally oriented and generally based on social learning theory. Likewise, previous research nutrition and education are closely interlinked. It is commonly understood that good nutrition among adolescents is important for healthy growth and development. But in addition to good health and nutrition increase the adolescent's attention span, its learning capacity, and its ability to fully engage in educational experiences.

The purpose of the current study is to assess the influence of nutrition education on adolescent girls (13-16) years. The nutrition, health and education three essential pillars of development. Among the many pillars that form the basis of a thriving nation, three are particularly important: nutrition, health and education. School-based nutrition education - properly done - touches upon all of them. It almost goes without saying that health is important to development without it, a country and its population cannot function properly. ${ }^{3}$ The research objectives of the study are as follows: To assess the current nutritional awareness regarding balanced diet and physical activity of school going adolescent girls (13-16years). To provide the nutrition education regarding balanced diet and physical activity to the school going adolescent girls (13-16years). To determine the impact of nutrition education regarding balanced diet and physical activity on nutritional awareness of the selected adolescent.

\section{Methodology}

Nutrition is a major environmental influence on physical and mental growth and development in early life. The current study is to assess the influence of nutrition education regarding balanced diet and physical activity on adolescent girls (13-16) years. The present study was being carried out at Govt, girl's high school Lahore.

\section{Research design}

The design of the research study is derived from the research methodology. This study was cross-sectional mixed method survey research. The data reported here was collected to assessing the influence of nutrition education regarding balanced diet and physical activity on adolescent girls (13-16) years.

Gender;

Age:

Scale

$1=$ Strongly disagree $2=$ Disagree $3=$ Strongly agree $4=$ Agree $5=$ Don't Know 


\section{Sample}

Through systematic random sampling 30 students was taken from four sections of each class from Govt. Islamia girls high school Lahore, in order to take pre-test and post-test. Taking attendance sheet of each class from the in charge of class then setting scale that every fifth student will be selected. A systematic random sampling is a sample of size $\mathrm{n}$ drawn from a population of size $\mathrm{N}$ in such a way that every possible sample of size $n$ has the same chance of being selected. In this technique, each member of the population has an equal chance of being selected as subject. The dependent variable was adolescent girls and independent variable was nutrition education.

\section{Instrumentation}

Data was collected by using self-constructed questionnaire as a data collection instrument. Questionnaire included close ended questions. Close ended questions allow a respondent to select her answer from a given number of options. They were used to measure opinions, attitudes, or knowledge regarding balanced diet and physical activity among adolescent girls (13-16) years. The close ended questions are easy to use, score, and code for analysis on a computer. Because all subjects respond to the same options, standardized data are provided. Pre test and post test was taken to assess their nutritional knowledge regarding balance diet and physical activity among adolescents. Also explain through presentations their relevant terms such as food pyramid, my plate, food guide lines and the recommended dietary allowances of different kind of food practices regarding good nutrition with the help of visual aids and pictorial presentation.

\section{Data collection procedure}

The method of data collection is based on two main sources. First one is about the primary source which includes the questionnaires and interviews. In addition, the second data collection source is the secondary data source, which includes journals, published research data, articles and much other information that is on written form and valuable for the researcher.

\section{Data analysis}

Data analysis was done by using SPSS 20 and MS excel (Microsoft office Excel 2010, 2013). Both of these software's are interlinked with each other and have a facility to apply formulas to analyze the study. The MS excel was used for the Graphical representation of the research data. SPSS 20 software was used to evaluate the paired value test for results. The use of SPSS helps the researcher to make the research work more scientific and reliable In addition to this, SPSS software also be proved quite useful for the purpose of graphical representation of the raw data. With the help of the SPSS application, different graphs based on different complex data was drawn easily and effectively.

\section{Results}

Fruit and vegetable consumption in particular has received much attention. The diets high in fruit and vegetables are associated with lower risk of diseases. Therefore, promoting health during adolescence, meeting the recommendations for fruit and vegetable intake can have positive implications for long term health. ${ }^{4}$

The influence of nutrition education among adolescents about the fruits and vegetables is significant at $\alpha$ level of 0.005 . The mean values of fruits and vegetables post are $3.70 \pm 0.466$. Adolescent's knowledge improved significantly about the importance of fruits and vegetables. After assessing the influence of nutrition education adolescent knows fruits and vegetables are essential for healthy and balanced diet. They have also significant knowledge that fruits and vegetables are good for eyes and skin. Also fruits and vegetables are rich source of vitamins and minerals that are helpful for fighting against infections and diseases in our body, as shown in Table 1.

Table I Questionnaire

\begin{tabular}{llllll}
\hline Questions & I & 2 & 3 & 4 & 5
\end{tabular}

Fruits are helpful in fighting infections and diseases?

Vegetables are rich source of vitamins and minerals?

Bread and cereals are complete food?

Milk and milk products are good source of protein?

Physical activities are necessary for adolescents?

\section{Protein}

Protein needs of adolescents are influenced by the amount of protein required for maintenance of existing lean body mass and accrual of additional lean body mass during the adolescent growth spurt. ${ }^{5}$ The influence of nutrition education among adolescents about the protein is significant at $\alpha$ level of 0.005 . The mean values for protein preference

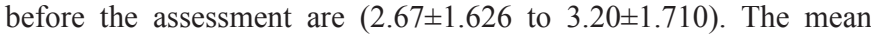
values for protein preference after the assessment are $(3.13 \pm 0.507$ to $3.33 \pm 0.606)$. The adolescent's knowledge improved significantly about the importance of protein. After assessing the influence of nutrition education adolescent knows protein is the essential energy source for muscle development. The adolescents have also significant knowledge that protein in the form of meat, poultry and fish are the main part of the balanced diet. Also meat, poultry and fish are rich source of protein that are helpful for the development of muscles and makes strong and healthy body immune system as presented in Table 2 .

Table 2 Fruits and vegetables

\begin{tabular}{|c|c|c|c|c|}
\hline List & Mean & $\mathbf{N}$ & $\begin{array}{l}\text { Std. } \\
\text { deviation }\end{array}$ & P-Value \\
\hline $\begin{array}{l}\text { Fruits are helpful } \\
\text { Fruits are helpful post }\end{array}$ & $\begin{array}{l}2.67 \\
3.7\end{array}$ & $\begin{array}{l}30 \\
30\end{array}$ & $\begin{array}{l}1.446 \\
0.466\end{array}$ & 0.001 \\
\hline $\begin{array}{l}\text { Good for eyes } \\
\text { Good for eyes post }\end{array}$ & $\begin{array}{l}2.23 \\
3.67\end{array}$ & $\begin{array}{l}30 \\
30\end{array}$ & $\begin{array}{l}1.194 \\
0.479\end{array}$ & 0 \\
\hline $\begin{array}{l}\text { Sources of vitamins and } \\
\text { minerals } \\
\text { Sources of vitamins and } \\
\text { minerals post }\end{array}$ & $\begin{array}{l}2.57 \\
3.6\end{array}$ & $\begin{array}{l}30 \\
30\end{array}$ & $\begin{array}{l}1.524 \\
0.498\end{array}$ & 0.003 \\
\hline $\begin{array}{l}\text { Good for skin } \\
\text { Good for skin post }\end{array}$ & $\begin{array}{l}2.1 \\
3.57\end{array}$ & $\begin{array}{l}30 \\
30\end{array}$ & $\begin{array}{l}1.094 \\
0.679\end{array}$ & 0.000 \\
\hline $\begin{array}{l}\text { Good source of energy } \\
\text { Good source of energy post }\end{array}$ & $\begin{array}{l}2.5 \\
3.57\end{array}$ & $\begin{array}{l}30 \\
30\end{array}$ & $\begin{array}{l}10480 \\
0.504\end{array}$ & 0.001 \\
\hline $\begin{array}{l}\text { Essential for healthy } \\
\text { balanced diet } \\
\text { Essential for healthy } \\
\text { balanced diet post }\end{array}$ & $\begin{array}{l}2.53 \\
0.053\end{array}$ & $\begin{array}{l}30 \\
30\end{array}$ & $\begin{array}{l}1.479 \\
0.507\end{array}$ & 0.003 \\
\hline
\end{tabular}


The impact of nutrition education regarding physical activity among adolescents is significant at $\alpha$ level of 0.005 . The adolescent's knowledge improved significantly after the nutrition education in areas such as importance of physical activity and the post mean value is $3.47 \pm 0.571$. The mean values of post different ways of physical activity is $3.10 \pm 0.662$. The mean value of post physical activity maintain the healthy status is $3.63 \pm 0.556$. Adolescents have also know that physical activity makes the body strong and build a healthy body status for a quality of life as presented in Table 2 .

The influence of nutrition education regarding balanced diet and physical activity among adolescents about the knowledge is significant at $\alpha$ level of 0.005 . Adolescent's knowledge improved significantly in areas such as balanced diet, meal consumption intervals and consumptions of fluids through-out the day. The mean values of pre assessment regarding balanced diet is $1.63 \pm 0.877$. The mean values of post assessment regarding balanced diet is $3.30 \pm 0.571$. The adolescents have also known that a diet that is composed of five food groups is balanced diet as showed in Table 3 .

Table 3 Protein

\begin{tabular}{lllll}
\hline List & Mean & N & $\begin{array}{l}\text { Std. } \\
\text { Deviation }\end{array}$ & P-Value \\
\hline $\begin{array}{l}\text { Main energy source for } \\
\text { muscle }\end{array}$ & 2.67 & 30 & 1.626 & 0.004 \\
$\begin{array}{l}\text { Main energy source for } \\
\text { muscle post }\end{array}$ & 3.13 & 30 & 0.507 & \\
$\begin{array}{l}\text { Meat and chicken source } \\
\text { Meat and chicken source }\end{array}$ & 3.2 & 30 & 1.71 & 0.005 \\
post & 3.33 & 30 & 0.606 & \\
\hline
\end{tabular}

\section{Balanced diet}

A well balanced diet improves the learning potential of adolescents, allows them to learn effectively. Good health and nutrition is the basic need to achieved adolescent's full educational potential because good nutrition effect on educational development and good learning ability of adolescents. ${ }^{6}$ The influence of nutrition education regarding balanced diet and physical activity among adolescents about the knowledge is significant at $\alpha$ level of 0.005 . Adolescent's knowledge improved significantly in areas such as balanced diet, meal consumption intervals and consumptions of fluids through-out the day. The mean values of pre assessment regarding balanced diet is $1.63 \pm 0.877$. The mean values of post assessment regarding balanced diet is $3.30 \pm 0.571$. The adolescents have also know that a diet that is composed of five food groups is balanced diet as showed in Table 4.

Table 4 Physical activity

\begin{tabular}{lllll}
\hline List & Mean & N & $\begin{array}{l}\text { Std. } \\
\text { deviation }\end{array}$ & P-Value \\
\hline Exercise is essential & 2.37 & 30 & 1.273 & 0 \\
Exercise is essential post & 3.47 & 30 & 0.571 & \\
Maintain healthy status & 2.37 & 30 & 1.273 & 0.000 \\
Maintain healthy status post & 3.63 & 30 & 0.556 & \\
Ways of physical activity & 2.2 & 30 & 1.157 & 0.001 \\
Ways of physical activity post & 3.1 & 30 & 0.662 & \\
\hline
\end{tabular}

\section{Nutritional knowledge}

The influence of nutrition education regarding balanced diet and physical activity among adolescents about the concept of nutrition, preference of junk food, importance of milk, obesity, meal skipping and intake of soda bottles and energy drinks is significant at the $\alpha$ level of 0.005 . Adolescent's knowledge improved significantly in areas such as junk food, intake of milk and source of Vitamin D as presented in Table 5.

Table 5 Balanced diet

\begin{tabular}{|c|c|c|c|c|}
\hline List & Mean & $\mathbf{N}$ & $\begin{array}{l}\text { Std. } \\
\text { Deviation }\end{array}$ & P-Value \\
\hline $\begin{array}{l}\text { Knowledge of balanced diet } \\
\text { Knowledge of balanced diet } \\
\text { post }\end{array}$ & $\begin{array}{l}1.63 \\
3.53\end{array}$ & $\begin{array}{l}30 \\
30\end{array}$ & $\begin{array}{l}0.809 \\
0.571\end{array}$ & 0 \\
\hline $\begin{array}{l}\text { Provides healthy life } \\
\text { Provides healthy life post }\end{array}$ & $\begin{array}{l}1.83 \\
3.57\end{array}$ & $\begin{array}{l}30 \\
30\end{array}$ & $\begin{array}{l}0.874 \\
0.504\end{array}$ & 0 \\
\hline $\begin{array}{l}\text { Meal should be consumed } \\
\text { after } 3 \text { to } 4 \text { interval per day } \\
\text { Meal should be consumed } \\
\text { after } 3 \text { to } 4 \text { interval per day } \\
\text { post }\end{array}$ & $\begin{array}{l}1.7 \\
3.3\end{array}$ & $\begin{array}{l}30 \\
30\end{array}$ & $\begin{array}{l}0.877 \\
0.535\end{array}$ & 0 \\
\hline $\begin{array}{l}\text { Consuming enough fluids } \\
\text { throughout the day } \\
\text { Consuming enough fluids } \\
\text { throughout the day post }\end{array}$ & $\begin{array}{l}1.8 \\
3.3\end{array}$ & $\begin{array}{l}30 \\
30\end{array}$ & $\begin{array}{l}0.761 \\
0.535\end{array}$ & 0 \\
\hline $\begin{array}{l}\text { Water intake per day } \\
\text { Water intake per day post }\end{array}$ & $\begin{array}{l}1.8 \\
3.3\end{array}$ & $\begin{array}{l}30 \\
30\end{array}$ & $\begin{array}{l}0.761 \\
0.466\end{array}$ & 0 \\
\hline
\end{tabular}

Table 6 Nutritional knowledge

\begin{tabular}{lllll}
\hline List & Mean & N & $\begin{array}{l}\text { Std. } \\
\text { Deviation }\end{array}$ & P-Value \\
\hline Meal skipping & 1.83 & 30 & 0.913 & 0.002 \\
Meal skipping post & 2.77 & 30 & 0.858 & \\
Sources of vitamin D & 1.7 & 30 & 0.915 & \multirow{2}{*}{0.001} \\
Sources of vitamin D post & 3.77 & 30 & 0.504 & \\
Junk food preference & 1.67 & 30 & 0.922 & \multirow{2}{*}{0.000} \\
Junk food preference post & 3.67 & 30 & 0.479 & \\
Canned food & 2.67 & 30 & 1.446 & \multirow{2}{*}{0.001} \\
Canned food post & 3.7 & 30 & 0.466 & \\
Obesity & 1.63 & 30 & 0.964 & 0.000 \\
Obesity post & 3.47 & 30 & 0.629 & \\
Soda bottles preference & 2.7 & 30 & 1.705 & \multirow{2}{*}{0.003} \\
Soda bottles preference post & 3.73 & 30 & 0.45 & \multirow{2}{*}{0.004} \\
Eating junk food & 3.03 & 30 & 1.691 & \multirow{2}{*}{0.002} \\
Eating junk food preference post & 3.63 & 30 & 0.49 & \\
Bones can be strong by milk & 2.67 & 30 & 1.516 & \\
Bones can be strong by milk post & 3.34 & 30 & 0.679 & \\
\hline
\end{tabular}

\section{Discussion}

The present results are in coherence with the findings of Story \& Stang $^{6}$ demonstrated that protein requirements per unit of height are highest for females in the 11 to 14 year age rang. The adolescents consume more than adequate amounts of protein according to national data on average, teens consume about twice the recommended level of protein and $31 \%$ of adolescent girls 14-18years of age consume more than twice the RDA for protein. When protein intakes are consistently inadequate, reductions in linear growth, delays in sexual maturation and reduced accumulation of lean body mass. 
The present findings are correlated with the work of Michels et al., reported that agreement between self-reported and parent-reported dietary and physical activity habits in subject. The main determinants of higher scores in subject were higher physical activity and higher awareness of human health $(\mathrm{P}<0.005)$. The subject's physical activity habits may be influenced by their parents' health awareness and other socio-economic characteristics. The intervention strategies, even in every subject, should also target parents in order to achieve maximum success.

Likewise, Pedersen S et al., ${ }^{8}$ investigated that adolescent girls have been identified as a key target population for physical activity behavior change. The average treatment effect for adolescent girls involved in physical activity interventions was significant $(\mathrm{P}<0.001)$. The interventions to increase physical activity in adolescent girls show small but significant effects, suggesting that behavior change may be challenging. The results showed that a clear decline in physical activity among girls starting in early adolescence. The physical activity is important for the healthy development of the body.

The current results are similar with the findings of Todd et al., ${ }^{9}$ who investigated that choosing wholegrain carbohydrates and consuming five serves of vegetables ( $1 / 2$ cup cooked vegetables or one cup salad is equivalent to one serve). Similarly, two servings of fruit per day were ensuring adequate fiber. The dairy group is the main source of dietary calcium and female adolescents require $3 \frac{1}{2}$ serves per day (one cup of milk, $3 / 4$ cup of yogurt, or two slices of cheese are equivalent to one serve).

The present results are in harmony with the findings of Todd et al., ${ }^{9}$ concluded that that adolescents benefit from a balanced diet that has $15 \%-25 \%$ of dietary energy from protein, $25 \%-35 \%$ of dietary energy from fat and $45 \%-65 \%$ of dietary energy from carbohydrate. This macronutrient profile enables a high diet quality score. Similarly, the inclusion of sufficient amounts of vegetables, fruit, whole grains, poultry, fish and reduced fat dairy products to meet vitamin and mineral requirements. The Protein recommendations can easily be achieved by including protein-rich foods such as lean meat, fish, eggs, or legumes at lunch and dinner. To meet the dietary fat recommendations, only a small amount of added fat may be required, as it is present in many other foods. Likewise, Tami ${ }^{10}$ demonstrated that a large percentage of adolescents reported eating less than the recommended amount of vegetables (71\%), fruits (55\%), and dairy foods $(47 \%)$.

The present results are in harmony with the findings of Preety \& Uma S Hiremath ${ }^{11}$ were made to assess the knowledge gain of students on selected subjects through given intervention and to analyze retention of knowledge gain through "before and after" experiment. Total mean score of pre-test (72.67) and post-test (83.48) of nutrition was compared and highly significant difference was found. Similarly, total mean score of health was found to be 69.31 in pre-test and 84.89 in post-test. The overall mean score of students with respect to knowledge about nutrition was 72.67 before intervention which increased to 82.44 after intervention.

The current results are in accordance with the findings of Luca et al., ${ }^{12}$ investigated that the study contributes to a more comprehensive understanding of what influences adolescent healthy eating, including the social influence of parents and friends. While also taking adolescent self-efficacy and outcome expectations into account. The study has a number of important implications such as healthy eating interventions should aim at strengthening self-efficacy and positive outcome expectations among adolescents. The family context should be included when implementing healthy eating interventions. Also the parents' awareness of their influence on their adolescent's healthy eating should be reinforced. Conclusively, it is clear that educational intervention had a significant impact on knowledge regarding both nutrition and health.

\section{Conclusion}

This study came to know that most of adolescents had a concept of nutrition and healthy diet. The nutrition is a major environmental influence on physical and mental growth and development in early life. Food habits of adolescents can influence on preferences and practices in later life. The current study support that good nutrition contributes to improving the wellbeing of adolescents and their potential learning ability. Thus nutrition education is contributing to better school performance. Adolescents, who learn healthy eating habits, are encouraged to be physically active and have the potential for reduced impact of chronic diseases in adulthood. Nutrition education is a key element to promoting lifelong healthy eating and exercise behaviours should start from the early stages of life.

\section{Acknowledgements}

None.

\section{Conflict of interest}

The author declares no conflict of interest.

\section{References}

1. Weare K. Diet, food and eating and the health promoting school. Health Education. 2015;115(2):126.

2. Barnes MJ, Casazza K, Austin H. Strategies to promote regular exercise in adolescent and young. Clinical Oncology in Adolescents and Young Adults. 2015;5:103-113.

3. Westenhoefer J. Establishing good dietary habits-capturing the minds of children. Public Health Nutr. 2001;4(1A):125-129.

4. Vereecken, Pedersen TP, Ojala K, et al. Fruit and vegetable consumption trends among adolescents from 2002 to 2010 in 33 countries. Eur $J$ Public Health. 2015;25(2):16-19.

5. Stang Jamie, Story Mary, Feldman. Nutrition in adolescent pregnancy. International Journal of Childbirth Education. 2005.

6. Katharina Widenhorn-Müller, Katrin Hille, Jochen Klenk, et al. Influence of Having Breakfast on Cognitive Performance and Mood in 13- to 20-Year-Old High School Students: Results of a Crossover Trial. Pediatrics. 2008;122(2):2.

7. Michels N, De Henauw S, Beghin L, et al. Ready-to-eat cereals improve nutrient, milk and fruit intake at breakfast in European adolescents. Eur J Nutr. 2015;55(2):771-779.

8. Pedersen S, Grønhøj A, Thøgersen J. Following family or friends. Social norms in adolescent healthy eating. Appetite. 2015;86:54-60.

9. Alwyn S Todd, Steven J Street, Jenny Ziviani, et al. Overweight and obese adolescent girls: The importance of promoting sensible eating and activity behaviors from the start of the adolescent period. Int J of Environ Res Public Health. 2015;12(2):2306-2329.

10. Videon TM, Manning CK. Influences on adolescent eating patterns: the importance of family meals. J of Adolesc Health. 2003;32(5):365-373.

11. Preety, Uma S Hiremath. Impact of nutrition and health education intervention on rural high school students. Karnataka J Agric Sci. 2015;28(1):92-95.

12. De Luca S, Schmeelk Cone K, Wyman P. Latino and Latina Adolescents' Help-Seeking Behaviors and Attitudes Regarding Suicide Compared to Peers with Recent Suicidal Ideation. Suicide and Life Threat Behav. 2015;45(5):577-587. 